
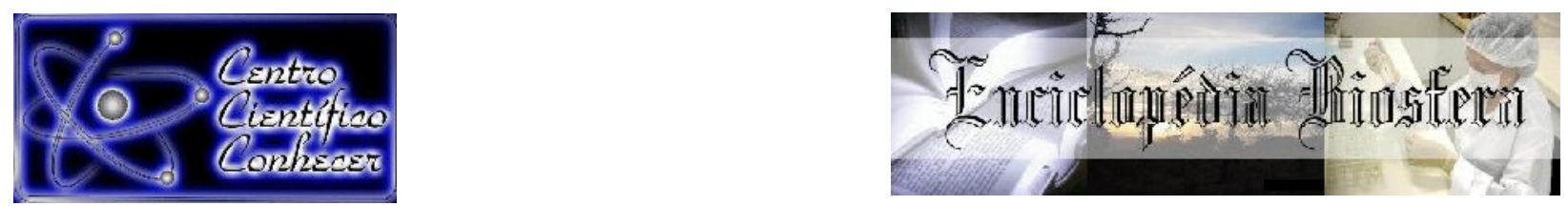

\title{
O INSOURCING COMO POSSÍVEL ESTRATÉGIA DE DESEMPENHO
}

Soraia Aidar ${ }^{1}$, Gracilene de Oliveira Pereira ${ }^{2}$, Vagner Rosalem ${ }^{3}$, Yuri da Silva Vaz ${ }^{4}$

${ }^{1}$ Mestranda em Gestão Organizacional pela Universidade Federal de Catalão

(UFCAT), Catalão, Goiás. E-mail: soraiaaidar@gmail.com

${ }^{2}$ Mestranda em Gestão Organizacional pela Universidade Federal de Catalão (UFCAT), Catalão, Goiás.

${ }^{3}$ Professor Doutor na Universidade Federal de Catalão (UFCAT), Catalão, Goiás.

${ }^{4}$ Aluno Especial no mestrado de Gestão Organizacional pela Universidade Federal de Catalão (UFCAT), Catalão, Goiás.

\section{Recebido em: 15/08/2021 - Aprovado em: 15/09/2021 - Publicado em: 30/09/2021 DOI: 10.18677/EnciBio_2021C35}

trabalho licenciado sob licença Creative Commons Attribution-NonCommercial-NoDerivatives 4.0 International License.

\section{RESUMO}

Objetivo: Sistematizar o conhecimento das razões que colaboram para que as empresas reformulem suas estratégias e passem a reconsider o insourcing em seus processos produtivos e as vantagens associadas. Método: Revisão integrativa da literatura que tem o objetivo de responder a seguinte questão norteadora: "Quais motivos levam as organizações a reconsiderarem a estratégia do insoursing em seus processos?" Os parâmetros de inclusão foram artigos científicos que contemplam a relação entre insoursing e outsourcing nas organizações, foram inseridos estudos publicados em português, inglês e espanhol, no período de 2015 a 2020. Os critérios de exclusão foram artigos de revisões integrativas, teses e dissertações. Os dados relevantes foram pesquisados a partir das origens de dados da Web of Science, Scientific Eletronic Library Online (SciELO) e Science Direct (ELSEVIER) , utilizou-se o operador booleano "AND". Foram analisados os cinco estudos encontrados. Resultados: O insourcing é uma possível estratégia de utilização em organizações de diferentes ramos de atuação, tais como: automobilística, têxtil, siderurgia, visando benefícios como enfrentamento das instabilidades da economia, aumento da capacidade produtiva, redução de custos e perpetuação da organização. Conclusão: Os resultados sugerem que as razões das empresas reavaliarem a utilização da estratégia do insourcing nos seus processos são: utilização da capacidade produtiva ao ponto de possibilitar a economia geral dos custos.

PALAVRAS-CHAVE: Estratégia. Insourcing. Outsourcing.

\section{INSOURCING AS A POSSIBLE PERFORMANCE STRATEGY: REVIEW SYSTEMATIC}

\begin{abstract}
Objective: Systematize knowledge of the reasons that help companies to reformulate their strategies and start to reconsider insourcing in their production processes and the associated advantages. Method: Integrative literature review that aims to answer the following guiding question: "What reasons lead organizations to reconsider the insourcing strategy in their processes?" The inclusion parameters were scientific
\end{abstract}


articles that contemplate the relationship between insourcing and outsourcing in organizations, studies published in Portuguese, English and Spanish were included, from 2015 to 2020 . The exclusion criteria were integrative review articles, theses and dissertations. Relevant data were searched from the Web of Science, Scientific Electronic Library Online (SciELO) and Science Direct (ELSEVIER) data sources, using the Boolean operator "AND". The five studies found were analyzed. Results: Insourcing is a possible strategy for use in organizations from different fields of activity, such as: automotive, textile, steel, aiming at benefits such as cost reduction and organization perpetuation. Conclusion: The results suggest that the reasons for insourcing were the same as those indicated for outsourcing.

KEYWORDS: Insourcing. Outsourcing. Strategy.

\section{INTRODUÇÃO}

A globalização tem como uma das principais características tornar o acirramento da concorrência mais intenso, obrigando as empresas a buscarem estratégias que visem o aumento da produtividade, inovação dos processos ou produtos e, consequentemente melhores resultados com menores custos (BENMEHAIA; BRABEZ, 2016). Para Caldeira (2018), a política econômica e social, em que grande parte das organizações atualmente estão inseridas, são determinadas por fatores que dificultam a transformação. A globalização é considerada a maior delas, impulsionando de forma excepcional as relações entre as organizações.

A adoção da competitividade possibilita não apenas a sobrevivência das organizações como também um diferencial competitivo e uma atuação superior à dos concorrentes. Com a instabilidade do padrão de produção em escala e da transformação para o sistema de fabricação flexível, conhecida ainda como fabricação enxuta, originou-se um desequilíbrio produtivo/administrativo nas instituições, nascendo assim à concepção de terceirização que atribui à prática de delegar a responsabilidade de uma tarefa/operação, ou até mesmo de um estágio produtivo, para outra empresa (RAYCIKI et al., 2016).

A qualidade no desenvolvimento do trabalho passa a ser um elemento estratégico que confere um diferencial competitivo às empresas que procuram constantemente alcançá-lo, mantê-lo e inová-lo. Porter (1990), define vantagem competitiva como o estabelecimento de uma posição favorável, rentável e sustentável no segmento, a qual diferencia a empresa de seus concorrentes. $O$ autor acrescenta que para que as organizações sobrevivam em um cenário demasiadamente competitivo, as instituições devem possuir estratégia competitiva, explícita ou implícita e superioridade competitiva em relação aos seus concorrentes, é percebida pelo mercado (sob a perspectiva dos consumidores ou dos opositores) como um valor extraordinário oferecido aos clientes ou ao menor custo possível.

Segundo Hitt et al. (2019), a sustentação de vantagem competitiva é gerada pelas distinções que a organização detém em relação aos concorrentes. Neste contexto, nas últimas décadas, essa prática de terceirizar se disseminou no ambiente produtivo, ganhando prestígio no meio das empresas perante a perspectiva estratégica, com vários intuitos, dentre estes se destacam a melhoria dos processos e a contenção de custos, além do emprego exclusivo de foco às atividades-principais (BENMEHAIA; BRABEZ, 2016).

Para crescer e desenvolver no médio e curto prazo, as entidades necessitam focar no core competence, ou seja, aquilo que a empresa faz melhor. Terceirizar as atividades que não fazem parte da sua competência principal é uma das iniciativas 
que as organizações devem adotar. O surgimento da terceirização ocorreu nos Estados Unidos por volta de 1940, durante a Segunda Guerra Mundial, quando as empresas incumbidas pela fabricação de material bélico para as "forças aliadas" passaram a transferir às outras empresas algumas atividades de suporte à produção de armamento, reservando para si somente os processos essenciais. Esse processo se solidificou no pós-guerra como uma prática de gestão conhecida como downsizing (reestruturação/enxugamento de estruturas) ou outsourcing (desverticalização; descarte das atividades menos rentáveis) (RAYCIKI et al., 2016).

No Brasil, a terceirização está presente desde a década de 1950. Esse movimento se ampliou no início dos anos de 1990, motivado pela forte recessão e a crise econômica estabelecida no País no fim dos anos 1980 (BENMEHAIA; BRABEZ, 2016).

Desde as crises vividas pelas indústrias do século $X X$, motivadas por um cenário competitivo global muito instável e turbulento, as organizações foram obrigadas a revisitarem as técnicas de contratações, possibilitando o surgimento de uma nova estratégia denominada desterceirização, ainda renomada de primarização: insourcing, outsorcing reverse ou re-insourcing. Nessa modalidade de re-insourcing aconteceu o procedimento inverso da terceirização, que reside em retornar as atividades que tinham sido terceirizadas para os processos internos da organização (BENMEHAIA; BRABEZ, 2016).

Estudos destacam que algumas organizações, após reavaliarem 0 posicionamento competitivo, modificaram as táticas de terceirização, gerando novas possibilidades de progresso, produção, consumo e abastecimento de infraestruturas e mercadorias (BENMEHAIA; BRABEZ, 2016). Desse modo, este estudo teve como objetivo sistematizar o entendimento gerado a respeito de como as entidades vêm se apropriando da estratégia do Insourcing e compreender quais as prováveis vantagens advindas desse novo processo.

\section{MATERIAL E MÉTODOS}

Este estudo refere-se à Revisão Integrativa da Literatura (RIL) que tem como objetivo sintetizar o entendimento das razões que colaboram para que as instituições reformulem as estratégias e passem a reconsider o insourcing em processos produtivos e as vantagens associadas nesse contexto. Seguiu precisamente as etapas do método apresentado por Whittemore e Knafl (2005) arroladas a seguir: elaboração da questão da investigação; estruturação de procedimentos para a coleta de dados; escolha dos revisores das pesquisas que compreendem a amostra final; análise e comparação dos achados dos artigos elegidos; síntese e construção dos resultados e apresentação da revisão integrativa como uma investigação crítica da bibliografia acadêmica (SHAMOROVA; CUMMINGS, 2017).

Os dados foram coletados entre cinco a 30 de junho de 2021, em que os pesquisadores, sistematicamente, buscaram artigos de forma combinada na seguinte base de dados: Web of Science, Scientific Eletronic Library Online (SciELO) e Science Direct (ELSEVIER), empregando-se os descritores controlados: "Cost", "Strategy". Além disso, foi utilizado o descritor não controlado: "Insourcing", levando em consideração que a terminologia "Insourcing" não está no catálogo de descritores controlados em Ciências da Saúde (DeCS) da Biblioteca Virtual em Saúde (BVS), o que possibilitou assim melhor escolha dos estudos a serem investigados.

Incluíram-se os artigos científicos indexados nessas bases de dados com textos científicos completos, originais, publicados entre $1^{\circ}$ de janeiro de 2015 a 30 de dezembro de 2020, gratuitos, disponíveis eletronicamente, nos idiomas português, 
inglês e espanhol, com resumo disponível que empregaram exclusivamente modelo epidemiológico e que delineassem o instrumento do conhecimento. O motivo da seleção deste intervalo decorreu em virtude de efetuar a revisão integrativa de estudos mais atuais e como justificativa pela utilização dos idiomas, foi com o intuito de comprender como a estratégia de utilização do insourcing vem sendo empregada nas corporações de outros países. As obras precisariam tratar do método do insourcing na fábrica utilizando referenciais da literatura (acadêmica/científica) que suportassem a metodologia e com aplicabilidade a uma comunidade representativa, além de demonstrarem resultados práticos do estudo. Nessa análise foram eliminados os artigos duplicados, estudos conceituais de atualizaçao, revisão, tese e dissertação.

Inicialmente, foram constatadas 33 publicações na base de dados Web of Science; nenhuma publicação no Scientific Eletronic Library Online (SciELO) e três publicações no Science Direct (ELSEVIER), totalizando 36 publicações. Após leitura do título ou resumo dos artigos foram selecionadas 23 publicações e destas, cinco foram excluídas por serem revisões ou estudos, restando 18 publicações para verificação de parâmetros de incorporação. Em seguida, após criteriosa análise, 13 artigos foram excluídos por não respeitarem os padrões de inserção. Realizou-se a hand search nos cinco estudos eleitos, ou seja, busca manual de artigos científicos tendo como origem as recomendações editoriais previamente escolhidas e não foi acrescentado nenhum estudo, permanecendo assim os cinco artigos que compuseram a presente revisão, conforme representado no fluxograma (Figura 1).

Com base nas conclusões das escritas que cumpriram os parâmetros de inclusão previamente definidos, realizou-se a leitura dos resumos e retirada das informações relevantes. Para cada estudo selecionado na amostra final, preencheuse o formulário moldado e apresentado por Ursi e Gavão (2005), extraindo e reproduzindo as informações em instrumento produzido e validado para esse fim. Recolheu-se desse mecanismo os seguintes dados: autoria, denominação do artigo, nível de evidência; amostra (n); instrumento utilizado; palavras-chave; país de origem, ano de publicação, base de dados, limitação do estudo; resultados da investigação original e sumário das conclusões.

Quanto ao grau de evidência foi utilizada a divisão hierárquica com nível I evidência alcançada através de resultado metanálise de estudos clínicos randomizados e controlados; nível II - evidências alcançadas através de estudo experimental individual; nível III - evidências obtidas de pesquisas quase experimentais como grupo único, não randomizados, controlado com pré e pósteste, ou estudo tipo caso controlado; nível IV - evidências conseguidas de estudos não experimentais, como pesquisa descritiva correlacional com abordagem de metodologia qualitativa; nível $\mathrm{V}$ - evidências atingidas de apresentações de casos ou exposiçoes de experiências; nível $\mathrm{VI}$ - evidências fundamentadas em pontos de vista de especialistas ou conforme diretrizes ou aspectos legais. A seguir fluxograma da figura 1 e figura 2 . 
FIGURA 1. Síntese de busca de acordo com as bases de dados, para Revisão Integrativa sobre Insourcing como possível estratégia de desempenho. Goiás-Brasil, 2020.

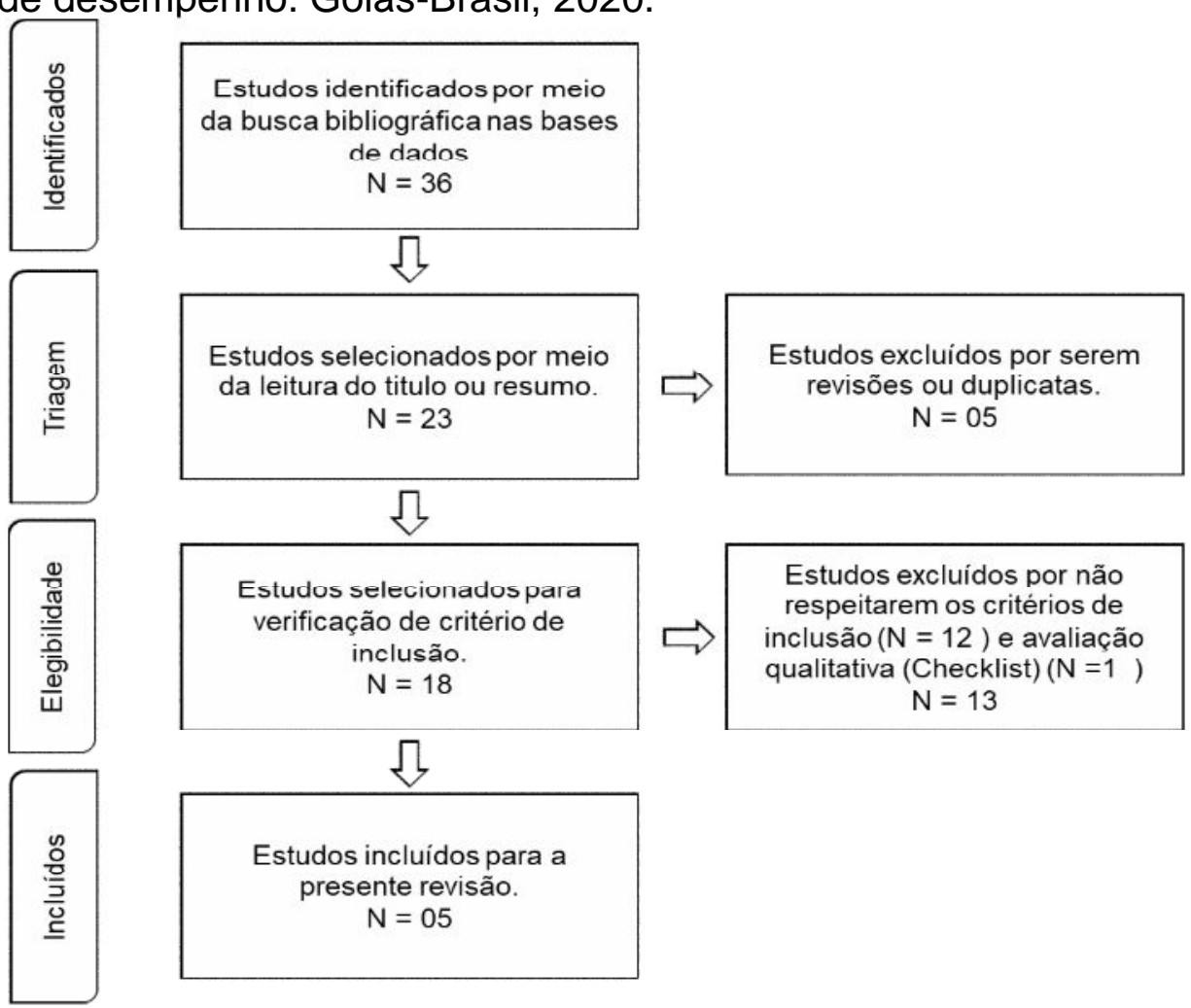

Fonte: Os autores (2021).

FIGURA 2 - Fluxograma de identificação e triagem de artigos de relevantes, em conformidade com o PRISMA Statement, para Revisão Integrativa sobre Insourcing como possível estratégia de desempenho. Goiás-Brasil, 2020.

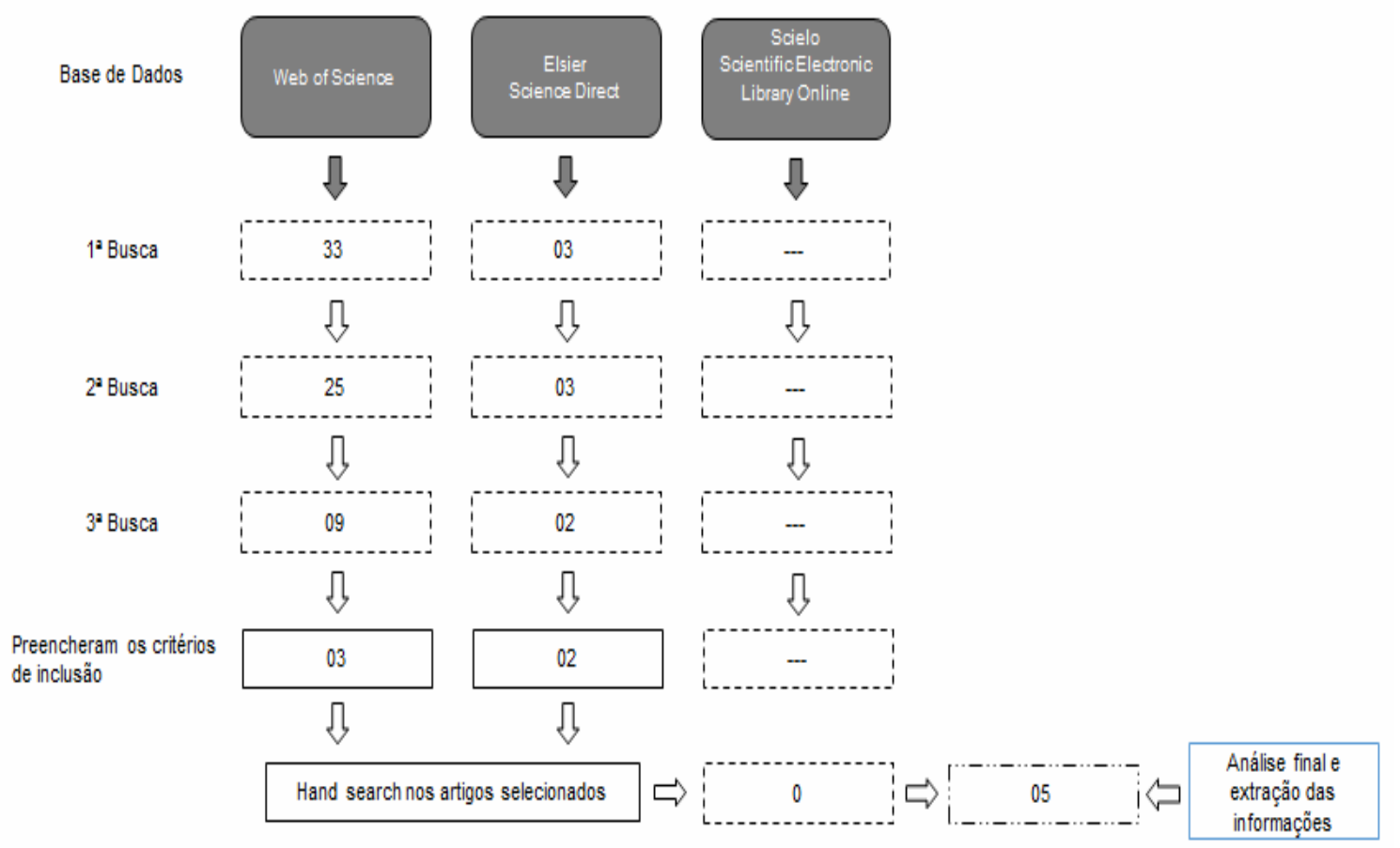

Fonte: Os autores (2021). 


\section{RESULTADOS E DISCUSSÃO}

Conforme os critérios relacionados à amostra dessa Revisão Integrativa (RI) resultaram em três estudos na Web of Science e dois artigos no Science Direct (ELSEVIER), totalizando cinco artigos para investigação. Dessa análise observou-se que $92,0 \%$ dos estudos encontravam-se na base de dados Web of Science e 8,0\% na Science Direct. Quanto ao idioma foi observado que $91,66 \%$ dos estudos estavam em inglês, $5,56 \%$ em português e $2,76 \%$ em espanhol, conforme gráficos 1 , 2 e 3 , abaixo identificados.

GRÁFICO 1: Artigos sobre Insourcing como possível estratégia de desempenho no período de 2015 a 2020, publicados por base de dados. (Distribuição por base de Dados)

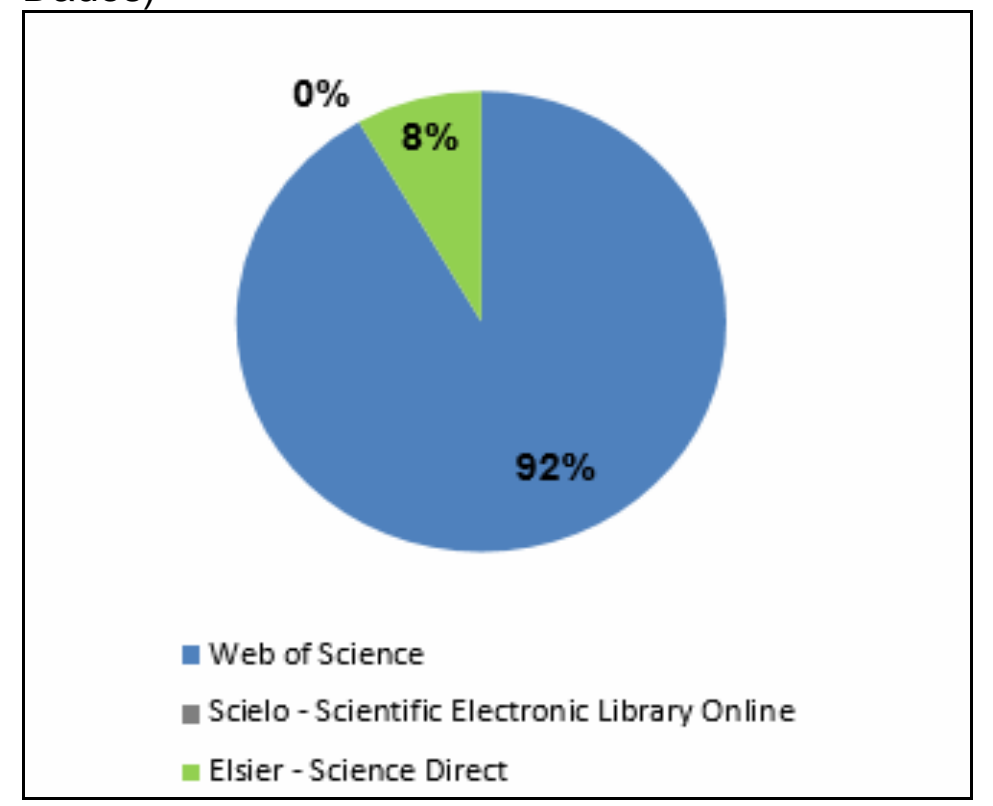

Fonte: Os autores (2021).

GRÁFICO 2: Artigos sobre Insourcing como possível estratégia de desempenho no período de 2015 a 2020 - Idioma

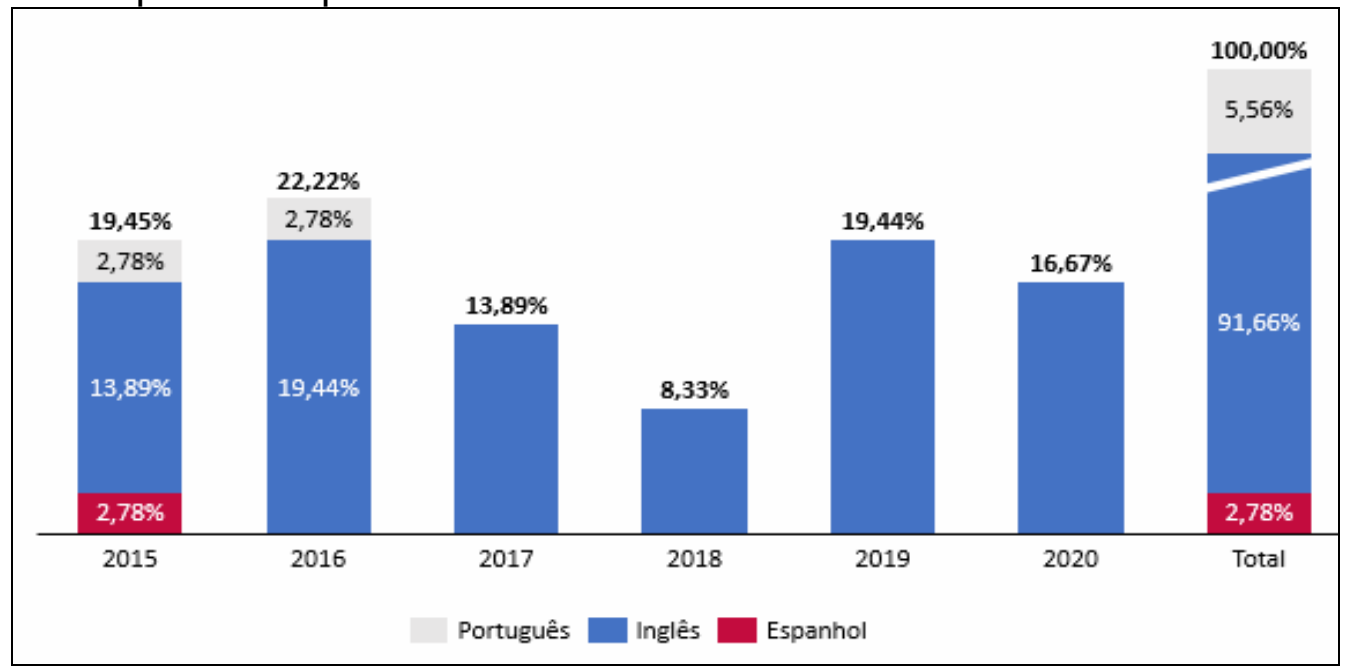

Fonte: Os autores (2021). 
GRÁFICO 3: Artigos sobre Insourcing como possível estratégia de desempenho no período de 2015 a 2020 - base de dados e ano de lançamento.

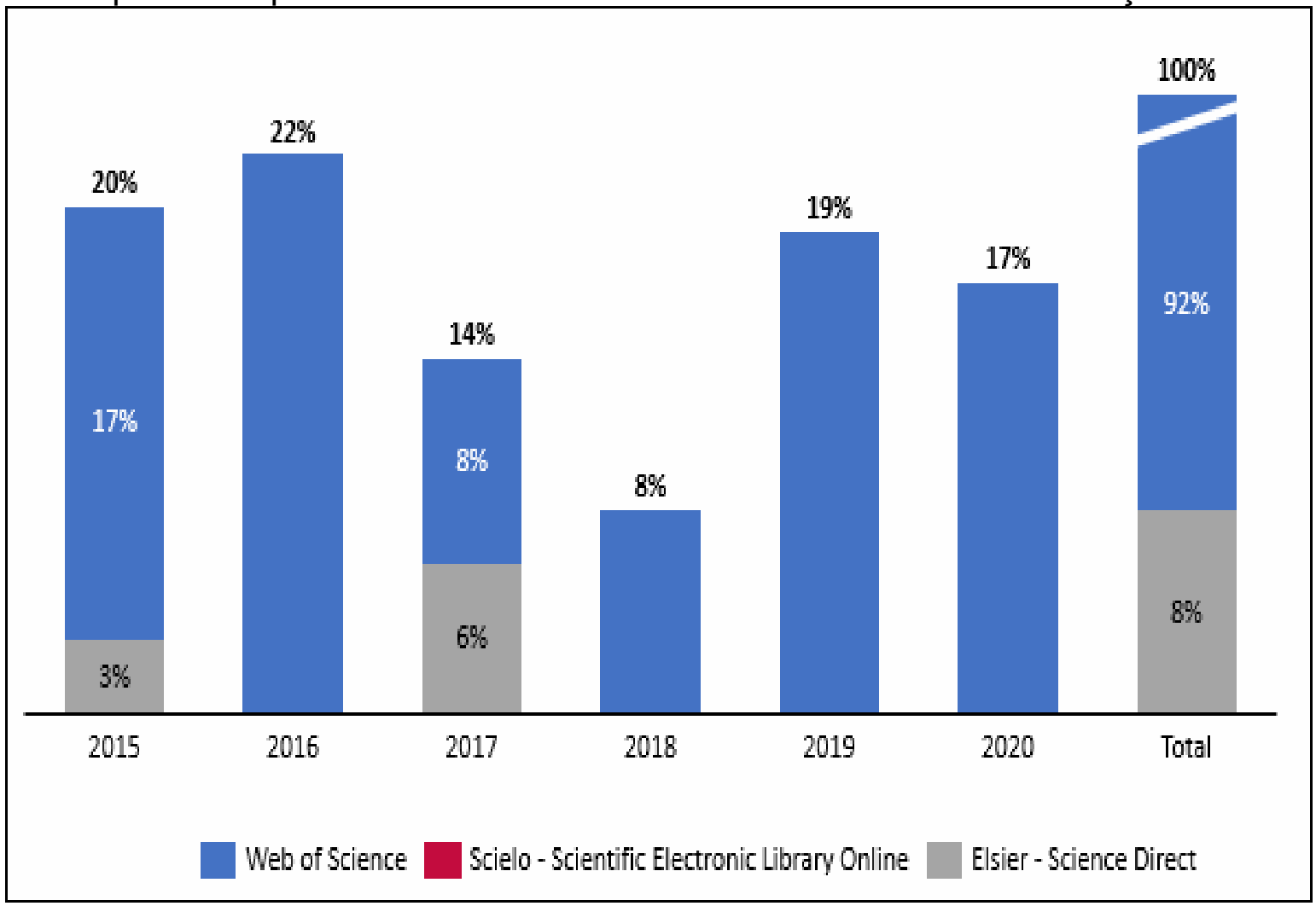

Fonte: Os autores (2021).

Com o intuito de resumir e complementar as descobertas desta RI, bem como evidenciar as contribuições desse tema, foi elaborado um quadro síntese, com informações do periódico em que o estudo foi publicado, o País onde a pesquisa foi desenvolvida, a autoria e o idioma do artigo, conforme Quadro 1 a seguir.

QUADRO 1: Síntese relativa aos cinco artigos que empregaram o Insourcing como possível estratégia de desempenho nas organizaçoes - 2015/2020.

\begin{tabular}{|c|c|c|c|c|c|}
\hline Título & Autoria & $\begin{array}{c}\text { Delineaçã } \\
\text { o do } \\
\text { estudo }\end{array}$ & $\begin{array}{c}\text { Ano / País / } \\
\text { Base de } \\
\text { dados }\end{array}$ & Resultados & $\begin{array}{c}\text { Síntese de resultados } \\
\text { finais }\end{array}$ \\
\hline $\begin{array}{l}\text { Primarização } \\
\text { como } \\
\text { Estratégia de } \\
\text { Redução de } \\
\text { Custos: uma } \\
\text { Metodologia } \\
\text { para } \\
\text { Identificar e } \\
\text { Mensurar os } \\
\text { Fatores que } \\
\text { Suportam a } \\
\text { Decisão. }\end{array}$ & $\begin{array}{l}\text { SANTOS, } \\
\text { Geraldo } \\
\text { Magela } \\
\text { Ribeiro dos; } \\
\text { TEIXEIRA, } \\
\text { Arilton }\end{array}$ & $\begin{array}{l}\text { Estudo de } \\
\text { Caso, } \\
\text { Nível IV }\end{array}$ & $\begin{array}{l}2015 \text { / } \\
\text { Brasil / Web } \\
\text { of Science }\end{array}$ & $\begin{array}{l}\text { A primarização } \\
\text { pode ser } \\
\text { utilizada como } \\
\text { estratégia de } \\
\text { otimização de } \\
\text { custos; } \\
\text { Nesse estudo de } \\
\text { caso a } \\
\text { primarização } \\
\text { trouxe uma } \\
\text { redução de } \\
\text { custos na ordem } \\
\text { de } 24,41 \% \\
\text { equivalente a R } \$ \\
1.293 .681,38 \text { por } \\
\text { mês. }\end{array}$ & $\begin{array}{l}\text { Os ganhos de salários e } \\
\text { benefícios obtidos nas } \\
\text { Convenções Coletivas } \\
\text { de Trabalho nos últimos } \\
10 \text { anos foram os } \\
\text { responsáveis pelo } \\
\text { aumento de custos dos } \\
\text { serviços terceirizados e } \\
\text { inviabilizaram a } \\
\text { terceirização. } \\
\text { Se os preços dos } \\
\text { serviços de terceiros } \\
\text { fossem corrigidos } \\
\text { apenas pela inflação } \\
\text { (INPC), nos últimos dez } \\
\text { anos, a primarização } \\
\text { dos serviços sob a ótica } \\
\text { de custos, seria } \\
\text { inviabilizada. }\end{array}$ \\
\hline
\end{tabular}




\begin{tabular}{|c|c|c|c|c|c|}
\hline Título & Autoria & $\begin{array}{c}\text { Delineaçã } \\
\text { o do } \\
\text { estudo }\end{array}$ & $\begin{array}{c}\text { Ano / País / } \\
\text { Base de } \\
\text { dados }\end{array}$ & Resultados & $\begin{array}{c}\text { Síntese de resultados } \\
\text { finais }\end{array}$ \\
\hline $\begin{array}{l}\text { Innovation } \\
\text { advantage: } \\
\text { insourcing } \\
\text { engineering }\end{array}$ & $\begin{array}{l}\text { CHAUDHU } \\
\text { RY, } \\
\text { Reuben; } \\
\text { GERDEMA } \\
\text { NN Dieter; } \\
\text { KAPOOR } \\
\text { Bharat }\end{array}$ & $\begin{array}{l}\text { Estudo de } \\
\text { Caso, } \\
\text { Nível IV }\end{array}$ & $\begin{array}{l}2015 / \\
\text { Estados } \\
\text { Unidos / } \\
\text { Web of } \\
\text { Science }\end{array}$ & $\begin{array}{l}\text { Ao internalizar a } \\
\text { área de } \\
\text { engenharia, a } \\
\text { empresa pode } \\
\text { igualar ou } \\
\text { superar as } \\
\text { vantagens de } \\
\text { custos imediatos } \\
\text { da terceirização. }\end{array}$ & $\begin{array}{l}\text { Com o avanço da } \\
\text { internet das coisas cria- } \\
\text { se novas } \\
\text { oportunidades para } \\
\text { diferenciar quase tudo } \\
\text { que as empresas } \\
\text { possam produzir, a } \\
\text { engenharia inovadora } \\
\text { para alcançar } \\
\text { conectividade, } \\
\text { funcionalidade e } \\
\text { invulnerabilidade } \\
\text { superiores torna-se } \\
\text { crítica para a vantagem } \\
\text { competitiva. }\end{array}$ \\
\hline $\begin{array}{l}\text { Bring it } \\
\text { back? An } \\
\text { examination } \\
\text { of the } \\
\text { insourcing } \\
\text { decision. }\end{array}$ & $\begin{array}{l}\text { HARTMAN, } \\
\text { L, Paul; } \\
\text { OGDEN, } \\
\text { J.A, Jeffrey; } \\
\text { HAZEN, } \\
\text { B.T, } \\
\text { Benjamin } \\
\text { (a) }\end{array}$ & $\begin{array}{l}\text { Estudo de } \\
\text { Caso, } \\
\text { Nível IV }\end{array}$ & $\begin{array}{l}2017, \\
\text { Estados } \\
\text { Unidos / } \\
\text { Science } \\
\text { Direct }\end{array}$ & $\begin{array}{l}\text { O Insourcing é } \\
\text { utilizado como } \\
\text { ferramenta para } \\
\text { corrigr falhas de } \\
\text { contratação do } \\
\text { outsourcing. } \\
\text { Os cenários que } \\
\text { motivaram o } \\
\text { insourcing são } \\
\text { predominanteme } \\
\text { nte idênticos aos } \\
\text { utilizados para o } \\
\text { outsourcing. } \\
\text { Imcompreensão } \\
\text { dos custos } \\
\text { integrais. }\end{array}$ & $\begin{array}{l}\text { As decisões são } \\
\text { tomadas para reduzir } \\
\text { gastos, aprimorar a } \\
\text { qualidade e a } \\
\text { produtividade. }\end{array}$ \\
\hline $\begin{array}{l}\text { Desterceiriza } \\
\text { ção como } \\
\text { Estratégia de } \\
\text { Negócio }\end{array}$ & $\begin{array}{l}\text { FERNANDE } \\
\text { S, Sara da } \\
\text { Costa; } \\
\text { SILVA, } \\
\text { Larissa } \\
\text { Juliana da; } \\
\text { PAIXÃO, } \\
\text { Jamile } \\
\text { Araújo; } \\
\text { ROSALÉM, } \\
\text { Vagner } \\
\end{array}$ & $\begin{array}{l}\text { Estudo de } \\
\text { Caso, } \\
\text { Nível IV }\end{array}$ & $\begin{array}{l}2016 \text { / } \\
\text { Brasil / Web } \\
\text { of Science }\end{array}$ & $\begin{array}{l}\text { Os principais } \\
\text { fatores que } \\
\text { levaram a } \\
\text { primarizar a linha } \\
\text { de montagem e } \\
\text { balanceamento } \\
\text { de pneus de } \\
\text { uma montadora, } \\
\text { foi a otimizaçao } \\
\text { e mitigação dos } \\
\text { gastos totais. }\end{array}$ & $\begin{array}{l}\text { Redução de custos de } \\
\text { produção. } \\
\text { Modificações no cenário } \\
\text { e escassez econômica. }\end{array}$ \\
\hline $\begin{array}{l}\text { Nearshoring, } \\
\text { reshoring, } \\
\text { and } \\
\text { insourcing: } \\
\text { Moving } \\
\text { beyond the } \\
\text { total costs of } \\
\text { ownership } \\
\text { conversation }\end{array}$ & $\begin{array}{l}\text { HARTMAN, } \\
\text { L, Paul; } \\
\text { OGDEN, A, } \\
\text { Jeffrey; } \\
\text { WIRTHLIN, } \\
\text { R, Joseph; } \\
\text { HAZENC, } \\
\text { Benjamin } \\
\text { T.(b) }\end{array}$ & $\begin{array}{l}\text { Estudo de } \\
\text { Caso, } \\
\text { Nível IV }\end{array}$ & $\begin{array}{l}2017, \\
\text { Estados } \\
\text { Unidos / } \\
\text { Science } \\
\text { Direct }\end{array}$ & $\begin{array}{l}\text { Variedade na } \\
\text { cadeia de } \\
\text { suprimentos. } \\
\text { Melhoria de } \\
\text { produtividade e } \\
\text { qualidade }\end{array}$ & $\begin{array}{l}\text { Essencial conhecer o } \\
\text { processo de } \\
\text { suprimentos dos seus } \\
\text { possíveis fornecedores } \\
\text { em sua totalidade, } \\
\text { antes de tomar a } \\
\text { decisão de terceirizar. }\end{array}$ \\
\hline
\end{tabular}

Fonte: Os autores (2021).

As atividades que mostram importância estratégica e que têm performance elevada devem continuar sendo realizadas pela respectiva instituição e aquelas que mesmo detendo importância estratégica para a empresa, mas não apresentam 
desempenho competitivo face ao mercado externo pode ser terceirizada de imediato (HARTMAN, et al., 2017a).

Nas pesquisas constatou-se que existe uma discussão acerca de um método ainda pouco utilizado, sendo retratado pelos autores como uma nova alternativa para se empregar em organizações, o insourcing, principalmente nos cenários de instabilidades econômicas. Os estudos apontaram ainda que a vantagem competitiva e a inovação encontram-se prontamente ligadas à capacidade de evitar o vazamento de conhecimento. Dessa forma, deve-se analisar todo o cenário para identificar o instante mais adequado para implantar a primarização nas instituições (FERNANDES et al., 2016).

Em relação à origem dos estudos identificou-se que 60,0\% são dos Estados Unidos e dois $(40,0 \%)$ são do Brasil. No tocante ao nível de evidência, as descobertas identificaram que todos os artigos (100,0\%) foram classificados como nível IV, que estão relacionados aos estudos com métodos não experimentais ou estudos de casos.

Conforme os dados analisados o atingimento da redução de custos é frequentemente mencionado como a principal razão para a terceirização. Assim, a organização deve permanecer focada no controle de custos de terceirização de uma forma global como uma maneira de se manter competitiva diante dos cenários adversos.

Conforme os estudos, na perspectiva do insourcing prevaleceu impressões nas áreas de administração em três artigos (80,0\%), e engenharia com um artigo (20,0\%). Quanto à modalidade da revista científica ocorreu a predominância na divulgação internacional com três artigos $(80,0 \%)$, escritos em inglês e dois artigos $(20,0 \%)$ no idioma português. Quanto ao período de publicação, dois artigos foram publicados no ano de 2015 (40,0\%), dois em 2016 (40,0\%), um artigo publicado em $2017(20,0 \%)$ e não houve no intervalo de 2018 a 2020 artigos publicados que atendessem aos critérios do estudo.

A estratégia empresarial é o curso de ação que uma empresa adota para assegurar seus objetivos de desempenho como a sobrevivência, o tamanho que pretende alcançar, os concorrentes que deseja enfrentar ou o posicionamento de mercado que almeja alcançar (MAXIMIANO, 2011). No entendimento de Hartman et al. (2017a) a estratégia da organização é uma posição exclusiva e valiosa, e para a obtenção envolve um encadeamento de diferentes atividades. Percebeu-se que a tática da empresa está intimamente relacionada com as decisões e ações tomadas pela organização que impactam diretamente nos resultados.

Em função de intensiva pressão por corte de custos e melhoria da rentabilidade dos ativos, combinada com o acirramento da concorrência e ainda a crescente instabilidade econômica na década de 1980, as empresas tiveram que recorrer ao mercado externo para comprar produtos e serviços. Esse episódio rompeu com a tática das grandes organizações de realizarem internamente todas as etapas do estágio produtivo e, consequentemente, recorreram as organizações as quais detinham especialização e novas tecnologias para produzirem com menor custo (FERNANDES et al., 2016).

A desterceirização ou integração vertical orientam as organizações a grandiosidades e equilíbrio entre todas as etapas de operações. Tais fatores são essenciais para as instituições definirem estrategicamente quais operações regressarão a serem realizadas internamente e se isto é factível, considerando custos e recursos organizacionais. Os fatores que mais contribuíram para a primarização da manutenção eletromecânica em uma siderúrgica nacional foram os 
acordos coletivos de trabalho das contratadas que, nos últimos 10 anos, tiveram um aumento superior aos das contratantes, além da incidência de lucro, taxas de administração, impostos e benefícios sobre os custos da mão de obra (SANTOS; TEIXEIRA, 2015).

A primarização da engenharia não apenas ressuscita a inovação e a propriedade intelectual que diferenciam os líderes de mercado de resultados sustentáveis, como também amplia a produtividade e mantém as ideias em sigilo até a fase de produção, possibilitando assim a comercializaçao total (CHAUDHURY et al., 2015).

Devido à organização desconsiderar alguns custos no momento do outsourcing, essa estratégia não se mostrou competitiva e, por isso, algumas instituições têm reavaliado a adoção do insourcing com vista a atingir resultados: eficiência operacional e menor custo de produção (HARTMAN et al., 2017a).

No estudo sobre a desterceirização de processo de montagem e balanceamento de pneus de uma montadora, declararam que os motivos essenciais que colaboram para a decisão da empresa efetuar a desterceirização foram a otimização e a redução de custos totais de produção (FERNANDES et al., 2016). No âmbito do outsourcing, o principal benefício é o comando integral que a empresa atinge em relação a uma tarefa, em função da vigilância continuada, possibilitando a avaliação da qualidade na totalidade (HARTMAN et al., 2017a).

Percebeu-se que com os avanços em tecnologia, um mercado competitivo e progressivamente incerto, o insourcing vem sendo utilizado como estratégia para enfrentar as instabilidades da economia, aumentando a utilização da capacidade ao ponto de permitir a economia geral dos custos (FOERSTL et al., 2016). Em relação à área do conhecimento, os autores são especialistas de diferentes profissões, desde administradores de empresas a engenheiros e peritos de tecnologia da informação. Tal fato sugere que a primarização vem sendo estudada por especialistas e a aplicabilidade tem alcançado diversos segmentos, tais como: têxtil, mineração, siderurgia, automobilística e da informática.

De forma geral, os estudos na totalidade recomendaram avaliar a probabilidade em executar a tática do Insourcing antes de tomar a decisão de adotar o Outsourcing (terceirização), uma vez que quando não se faz uma análise detalhada, uma vantagem econômica, no curto prazo, pode ofuscar os benefícios de redução de custo real e sustentada no longo prazo (BESANKO et al., 2018).

A terceirização é importante dentro da empresa, mas a internalização também pode ser. O Outsourcing nada mais é do que a internalização de funções que vinham sendo exercidas fora da empresa, de forma que se alcancem melhorias no processo e vantagens competitivas em relação às outras empresas (SANTOS; TEIXEIRA, 2015).

Às vezes é possível que essa internalização seja considerada estratégia de custo, mas, em outras, é usada para aperfeiçoar o processo fazendo-o dentro da empresa por qualquer motivo. Não é trazer nenhuma atividade para dentro da organização, mas sim aquela atividade integrada que pode ser melhor assumida pela empresa, conseguindo maior benefício para os clientes, pois a empresa é capaz de realizá-la em determinado período (FERNANDES et al., 2016). Outra razão para fazer isso é que a empresa precisa redefinir a concepção de setor ou indústria.

Para ganhar espaço em novos domínios competitivos, a empresa tem que desenvolver os recursos de que dispõe, combinando-os com determinadas características estratégicas. Essa estratégia busca utilizar os recursos internos da organização, tornando-se mais competitiva (HARTMAN, et al., 2017a). 
Outras vantagens do insourcing são o desenvolvimento, retenção e valorização dos profissionais do setor a ser primarizado ou mesmo através da busca por talentos dentro da organização, fazendo com que a atividade seja executada da forma mais eficiente possível por pessoas capacitadas em determinado trabalho (LEE et al., 2019).

Deve-se levar em consideração que quem conhece a realidade da empresa é quem está dentro dela, e os outsiders não são capazes de entender certas rotinas, embora também seja verdade que existem atividades ou processos através dos quais a internalização não é possível. O talento será o melhor ativo para desenvolver determinadas atividades dentro da empresa e parte desses processos que devem ser realizados pode ser o trabalho de consultoria, em que às vezes os consultores são contratados para determinados aspectos que um trabalhador treinado dentro da empresa e são capazes de desenvolver de forma mais eficaz e com conhecimento absoluto dentro da empresa (SANTOS; TEIXEIRA, 2015).

Entre os benefícios do insourcing, ressalta-se que as tarefas são executadas mais rapidamente; as pessoas envolvidas na tarefa sabem melhor o que precisa ser feito, pois estão envolvidas na empresa e podem fazer melhor e mais rápido; os trabalhadores conhecem a missão, visão e valores da organização; não há intermediários (HARTMAN, et al., 2017a).

Ressalta-se que no insourcing os custos podem ser melhor controlados e otimizados, pois a empresa sabe exatamente o que está sendo feito em todos os momentos e há maior controle e monitoramento do processo, da produtividade e de tudo que está envolvido nas funções a serem desenvolvidas (FERNANDES et al., 2016).

Outros benefícios são que os funcionários se sentem envolvidos com os projetos da empresa; os funcionários podem se sentir mais motivados, sendo possível reconhecer capacidades ocultas até agora dos trabalhadores; os salários podem ter que ser aumentados, mas nenhum consultor externo precisa ser contratado; as funções podem ser desempenhadas conforme responsabilidade social corporativa; com maior retorno sobre o investimento; e a minimização da chance de fracasso e a maximização das chances competitivas (SANTOS; TEIXEIRA, 2015).

Não é aconselhável sobrecarregar o mesmo trabalhador com todas essas funções, caso contrário, seu desempenho pode ser reduzido. Além disso, é necessário reconhecer bem as tarefas que podem ser realizadas dentro da empresa separando-se daquelas que podem ser terceirizadas, fazendo um bom estudo das vantagens e desvantagens de cada decisão. Fatores como disponibilidade de mão de obra, processos estabelecidos, qualidade e custo são determinantes para esse diagnóstico e determinação do insourcing (FERNANDES et al., 2016).

Existem questões que a empresa deve resolver com o auxílio de consultoria externa. Em muitos casos, devem-se contratar especialistas externos para executar essa análise, pois eles podem contribuir com uma visão externa seguindo parâmetros de mercado, já em outros casos é possível escolher entre fazer ou terceirizar dentro da própria empresa.

Qualquer empresa, faça o que fizer, deve manter a contabilidade, seus livros obrigatórios em dia, registrar as contas anuais, apresentar autoavaliações e declarações fiscais, realizar todos os procedimentos para os trabalhadores como contratos, registros, cancelamentos, folha de pagamento, contribuições para a previdência social, etc (HARTMAN et al., 2017a). Essa necessidade pode ser terceirizada pela contratação de uma agência ou consultoria de negócios que realize 
essas funções. A vantagem desta forma é que a consultoria fornece toda a infraestrutura e coloca à disposição pessoal especializado em cada uma destas questões a um preço, normalmente, inferior ao que custaria se fosse realizado pela própria empresa, mas também é possível decidir que a atividade será realizada pela própria empresa, criando, para isso, o departamento correspondente (FERNANDES et al., 2016).

Desta maneira, a empresa deve ter trabalhadores com formação e experiência necessárias e dotá-los de infraestrutura de trabalho adequada em termos de espaços de trabalho, suportes físicos e informáticos, espaços de armazenamento, meios de comunicação, etc. Em ambos os casos, é necessário implementar protocolos de operação e comunicação com quem realiza a tarefa. A este exemplo podem ser adicionados inúmeros outros tais como: tarefas de marketing e publicidade, transporte, segurança ou limpeza das instalações, etc (HARTMAN, et al., 2017a).

A internalização ocorre quando uma dessas tarefas terceirizada passa a não ser tão eficiente e a empresa opta por realizá-la. Um exemplo seria as tarefas administrativas de contabilidade, impostos, folha de pagamento e outras que sejam retiradas da consultoria externa, para serem realizadas dentro da própria organização (RAYCIKI et al., 2016).

Se for realizada a internalização e, portanto, a empresa assumir tarefas que anteriormente havíam sido terceirizadas, será necessário ter os meios, a preparação, a experiência e as competências básicas para a realização dos trabalhos de forma eficaz e confiável. Por exemplo, se primarizar a contabilidade, deve-se ter os serviços de um trabalhador treinado para cuidar dessa área e não é correto confiar essa responsabilidade a alguém que não tenha o preparo necessário. Dessa forma, as empresas procuram fazer com que essa internalização seja assumida pelos trabalhadores que já prestam os seus serviços na empresa contratada, treinando-os nos conceitos e metodologias da organização. Isto tem vantagens, porque aquele trabalhador que já está no quadro de pessoal, conhece o ambiente da empresa e está familiarizado com os protocolos e sistemas que são utilizados (CHAUDHURY et al., 2015).

A capacitação do pessoal que já se encontra na empresa exigirá, em alguns casos, a requalificação profissional através de cursos, estágios e outras atividades que os preparem para a nova atividade, embora continue a ser necessário que sejam, desde antes, as pessoas certas. Tudo tem seus prós e contras, mas, em geral, percebe-se que as tarefas de internalização podem simplificar as tarefas que ganharão velocidade ao serem realizadas dentro da própria empresa (SANTOS; TEIXEIRA, 2015).

Além disso, evidenciou-se nos estudos que ao ponderar as oportunidades de mudar ou realocar a estratégia da desterceirização, o acesso a mais ampla base de informações é fundamental, pois são elas que darão suporte para que a decisão se mostre acertada no longo prazo, mediante a melhoria do desempenho da entidade em todos os aspectos (qualidade, produto, financeiro).

\section{CONCLUSÃO}

Com o tempo, a concepção de uma organização de sucesso evoluiu, passando de um modelo de negócio em que as instituições que administravam todos os seus processos e atividades internamente eram consideradas bem-sucedidas, para o extremo oposto. Dada a diversidade em que as organizações atualmente estão inseridas, para que tenham sucesso, desinvestir das atividades periféricas 
para se concentrar no núcleo do negócio, é uma das estratégias a ser considerada. Ao optar pelo outsourcing, na prática, a organização almeja criar uma vantagem competitiva em relação aos seus concorrentes, uma vez que ela tem a oportunidade de focar em suas atividades essenciais (core) e potencializar outras.

As organizações têm revisitado seus processos de contratação e a reconsideração do insourcing tem sido adotada como uma estratégia empresarial motivada por diversos fatores: melhoria da qualidade e da produtividade; possibilidade de redução do volume de acordos externos; complexidade da cadeia de valor; avanço da tecnologia frente a operações mais ágeis; redução de custos operacionais; incertezas políticas; extinção da submissão de fornecedores externos e atingimento de resultados sustentáveis da organização.

Nesta revisao integrativa da literatura, as maiores prevalências foram de artigos que utilizaram estudo de caso, que correspondem a análise de dados de forma detalhada de um caso particular que elucida a dinâmica do caso. A síntese das conclusões dos artigos favoreceu o entendimento de evidências, estimulando a transmissão de aprendizagem para a prática. Os achados apontam que o tema insourcing nas organizaçoes ainda tem um grande potencial de pesquisa.

No entanto, foi identificada uma lacuna de informações na construção do conhecimento a respeito do assunto, ao apurar-se carência de publicação e indexação nas bases de dados, uma vez que nos anos de 2015 a 2020 foram selecionados cinco estudos que respondessem aos padrões de incorporação e nenhum artigo nos anos de 2018 a 2020 foi encontrado.

Sugerem-se pesquisas futuras na investigação do objeto do estudo a fim de tornar a informação mais acessível e difundida para as organizações e toda a comunidade científica.

\section{REFERÊNCIAS}

BENMEHAIA, A. M.; BRABEZ, F. The Empirical Factors Determining Vertical Integration in Algerian Food Manufacturing Sector. European Scientific Journal, ESJ, v. $12, \quad$ n. 28, 2016. Disponível em: <http://dx.doi.org/10.19044/esj.2016.v12n28p\%25p>.

DOI: 10.19044/esj.2016.v12n28p252, Acesso em: 09 ago 2021.

BESANKO, D.; DRANOVE, D.; SHANLEY, M.; SHAEFER, S. A economia da estratégia. 5 ed. São Paulo: Editora. Brookman, 2018.

CALDEIRA. J. Monitorização da performance organizacional. 1. ed. Lisboa: Conjuntura Actual, 2018.

CHAUDHURY, Reuben; GERDEMANN, Dieter; KAPOOR, Bharat. Innovation advantage: insourcing engineering. Strategy \& Leadership. V. 43 n. 6, p. 3-9. Web of science. $2015 . \quad$ Disponível em: <https://www.emerald.com/insight/content/doi/10.1108/SL-08-20150066/full/html?fullSc=1>. doi: https://doi.org/10.1108/SL-08-2015-0066, Acesso em: 10 ago. 2021.

FERNANDES, C, S; SILVA, J, P, L; PAIXÃO, J, A; ROSALEM, V. Desterceirizaçao Como Estrategia de Negócio : Um Estudo de Caso. ENCICLOPÉDIA BIOSFERA, 2016, v.13, p. 1809-1816. Disponível em: < https://conhecer.org.br/ojs/index.php/biosfera/article/view/1153>. doi: 
10.18677/EnciBio_2016B_185, Acesso em: 10 ago. 2021.

FOERSTL, K.; KIRCHOFF, J. F.; BALS, L. Reshoring and insourcing: drivers and future research directions. International Journal of Physical Distribution \& Logistics Management, v. 46, n.5, p. 492-515, 2016. Disponível em: .DOI: 10.1108/IJPDLM02-2015- 0045.

HARTMAN, P. L.; OGDEN, J. A.; HAZEN, B. T. Bring it back? An examination of the insourcing decision. International Journal of Physical Distribution \& Logistics Management, v. 47, n. 2/3, p. 198-221, 2017. Disponível em: $<$ https://www.emerald.com/insight/content/doi/10.1108/IJPDLM-09-20150220/full/html>. doi: 10.1108/JJPDLM-09-2015-0220. Acesso em: 10 ago. 2021(a).

HARTMAN, P. L.; OGDEN, J. A.; WIRTHLIN, J. R.; HAZEN, B. T. Nearshoring, reshoring, and insourcing: Moving beyond the total cost of ownership conversation. Business Horizons, v. 60, n. 3 , p. 363-373, 2017. Disponível em: <https://doi.org/10.1016/j.bushor.2017.01.008>. doi: 10.1016/j.bushor.2017.01.008. Acesso em: 10 ago. 2021(b).

HITT, M. A.; IRELAND, D.; HOSKINSSON, R. E. Administração Estratégica: competitividade e globalização. São Paulo: Pioneira Thomson Learning, 2019.

LEE, G. R.; LEE, S.; MALATESTA, D.; FERNANDEZ, S. Outsourcing and organizational performance: the employee perspective. American Review of Public Administration, v. 20, n. 2, p. 1-14, 2019. Disponível em: <https://doi.org/10.1177\%2F0275074019855469. Acesso em 11 ago.2021.

MAXIMIANO, A.C.A.; Introdução a administração - 8. Ed., Sao Paulo: Atlas, 2011.

PORTER, M.E. Vantagem Competitiva: criando e sustentando um desempenho superior. 30. ed. Rio de Janeiro: Campus, 1990;

RAYCIKI, C.; EYERKAUFER, M. L.; MARIAN, S. Terceirização ou primarização: impactos no desempenho econômico e financeiro de uma empresa de serviços especializados. In: Anais do Congresso Brasileiro de Custos-ABC, 2016, Porto de Galinhas. Anais. Porto de Galinhas, PE, 2016.

SANTOS, G.M.R.; TEIXEIRA, A.; Primarização como Estratégia de Redução de Custos: uma Metodologia para Identificar e Mensurar os Fatores que Suportam a Decisão. Web of science, Rio de Janeiro, v. 10, n. 2, 2015. Disponível em: $<$ http://atena.org.br/revista/ojs-2.2.3-06/index.php/ufrj/article/viewArticle/2551> Acesso em: 10 ago. 2021.

SHAMOROVA D. P; CUMMINGS C. E. Participatory action research (PAR) with children and youth: an integrative review of methodology and PAR outcomes for participants, organizations, and communities. Child Youth Serv Rev: Elsevier, 2017, v.81 p.400-412. Disponível em: <https://www.sciencedirect.com/science/article/abs/pii/S0190740917302086?via\%3D ihub>. doi: https://doi.org/10.1016/j.childyouth.2017.08.022, Acesso em: 09 ago. 2021. 
URSI, E. S.; GAVÃO, C. M; Prevenção de lesões de pele no pré-operatório: revisão integrativa da literatura. Artigos de Revisão. Rev. Latino-Am. Enfermagem. Ribeirão Preto, São Paulo, 2005. Disponível em: < https://www.scielo.br/j/rlae/a/7hS3VgZvTs49LNX9dd85VVb/abstract/?lang=pt>. doi: https://doi.org/10.1590/S0104-11692006000100017, Acesso em: 09 ago. 2021.

WHITTEMORE, R., KNAFL, K. The integrative review: updated methodology. School of Nursing, Yale University, Connecticut, USA. J Adv Nurs. 2005 Dec; 52(5): 546-53. Disponível em: <https://pubmed.ncbi.nlm.nih.gov/16268861/>. doi: 10.1111/j.1365-2648.2005.03621.x, Acesso em: 09 ago. 2021. 